\title{
Zoster in healthy child: rare diagnosis
}

\section{Letter to Editor}

Varicella-zoster virus (VZV; human herpesvirus 3) is a herpes virus that causes infection in humans. The reactivation of latent VZV manifests as herpes zoster which occurs usually in immunocompromised and elderly individuals. ${ }^{1}$

Herpes zoster remains rare in early childhood and still rarer in infancy. ${ }^{2}$ The higher incidence of herpes zoster in immunocompetent children may be due to VZV vaccination, intrauterine exposure, penetrating trauma, emotional stress, and asthma. ${ }^{3}$

WE report a 20-month-old infant with herpes zoster affecting the right lumbar. A 20-month-old infant, having as antecedents chickenpox at age of 1 year, who had 4 days before admission, vesicular lesions at the right lumbar evolving in a context of fever.

The clinical examination found a child en good condition. The dermatological examination revealed multiple grouped vesicles with a cloudy content on an erythematous base spreading over the right lumbar and respecting the median line. The diagnosis of shingles was retained based on the clinical aspect of the lesions. The remainder of the examination did not show any neurological signs, lymphadenopathy or other signs. A minimal biological analysis was performed including a normal blood count, blood glucose and HIV serology.

Our patient received an oral antibiotic therapy in combination with symptomatic treatment, antiseptic and antipyretic, with a good improvement. Herpes zoster in infancy or early childhoodis a rare condition, due to reactivation of the latent varicella-zoster virus (VZV) infection. ${ }^{1}$
Volume 3 Issue 5 - 2019

\author{
Chaoui Rhizlane, Selma El Kadiri, Sara \\ Oukarfi, Zakia Douhi, Sara Elloudi, Hanane \\ Baybay, Fatima Zahra Mernissi \\ Department of Dermatology, CHU Hassan II, Morocco
}

\begin{abstract}
Correspondence: Chaoui Rhizlane, Department of Dermatology, CHU Hassan II, Fez, Morocco,

Email Chaoui.rhizlane@gmail.com
\end{abstract}

Received: October 03, 2019 | Published: October 31, 2019

Clinically herpes zoster can present as painful vesicular lesions on an erythematous base spread over 1 to 3 dermatomes in immunocompetent patients. The incidence of herpes zoster is higher in immunocompromised patients and in the elderly, with decreased cell-mediated immunity and with chronic diseases (diabetes, renal insufficiency, oncologic diseases).,

The reason for reactivation of VZV in healthy immunocompetent children can be the consequence of acquiring primary varicella infection in utero, or during early infancy. Vaccination with live attenuated virus may also contribute. ${ }^{5}$ Complications are rare type surinfection, depigmentation and ulceration. ${ }^{6}$ Antiviral (acyclovir) is the first choice treatment for immunocompromised children because of life-threatening complications. ${ }^{3}$ The case is being reported on account of the rarity of herpes zoster during infancy.
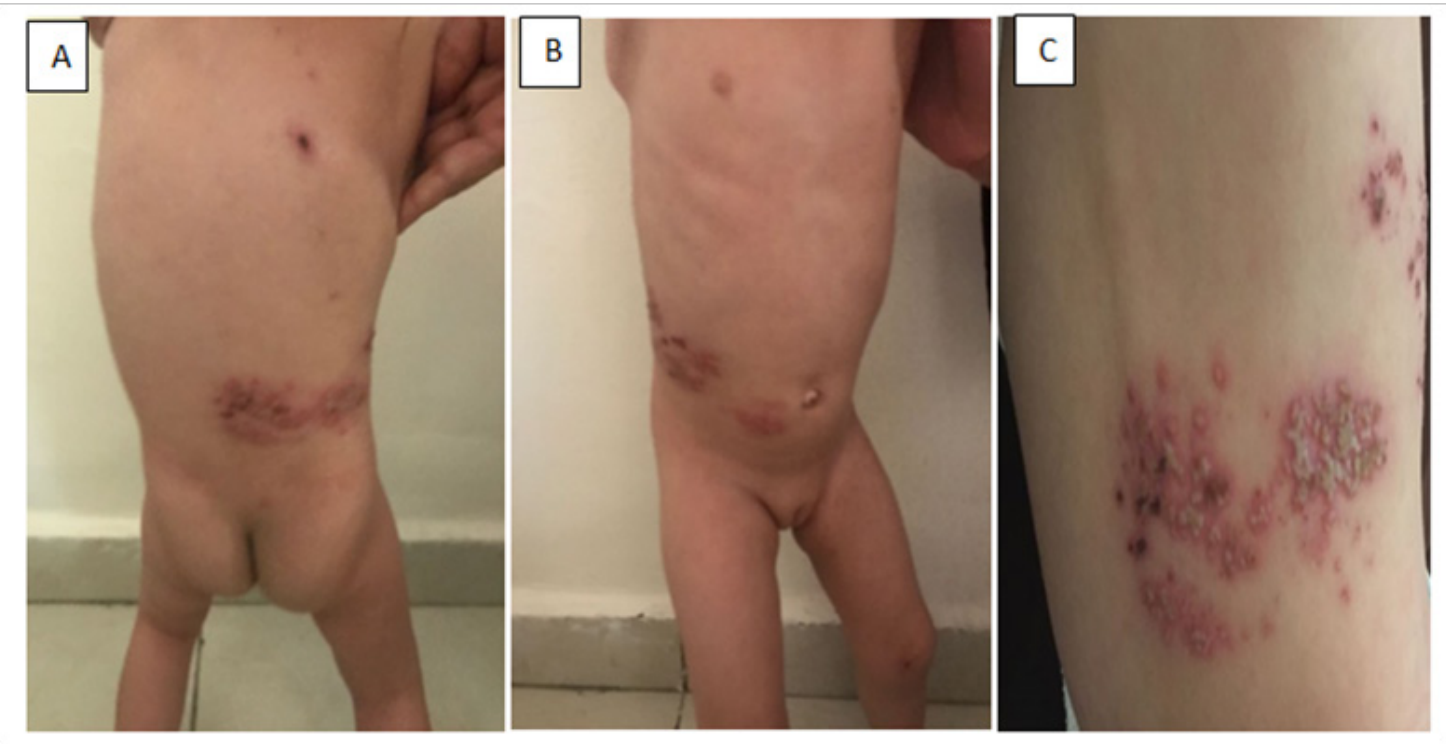

Figure I A,B,C: Multiple grouped vesicles on an erythematous base spreading over the right lumbar. 


\section{Acknowledgments}

None.

\section{Conflicts of interest}

The authors report no conflicts of interest.

\section{Funding}

None.

\section{References}

1. Katakam BK, Kiran G, Kumar U. A prospective study of herpes zoster in children. Indian J Dermatol. 2016;61(5):534-539.
2. Olubanjo OO. Herpes Zoster In A Healthy Nigerian Child: A Case Report. Internet J Pediatr Neonatol. 2007;9(1).

3. Kuchar E, Szenborn L, Lis I, et al. Clinical Presentation of Herpes Zoster in Immunocompetent and Immunocompromised Hospitalized Children Treated With Acyclovir. Journal of Pediatric Hematology/Oncology. 2016;38(5) :394-397.

4. O'Connor KM, Paauw DS: Herpes zoster. Emerg Med Clin North Am. 2013, 97(4):503-522.

5. Prabhu S, Sripathi H, Gupta S, Prabhu M. Childhood herpes zoster: A clustering of ten cases. Indian J Dermatol. 2009;54(1):62-64.

6. Schmader K. Herpes Zoster. Ann Intern Med. Review. Ann Intern Med. 2018:2;169(3): ITC19-ITC31. 